\title{
The Relationship between Emotional Intelligence and Emotional Maturity among Students of Kurdistan University of Medical Sciences
}

\author{
Modabber Arasteh ${ }^{1 *}$ and Seyedeh Asrin Seyedoshohadaei ${ }^{2}$ \\ ${ }^{1}$ Associate Professor of Psychiatry, Department of Psychiatry, Kurdistan University of Medical Sciences, Sanandaj, Iran \\ ${ }^{2}$ Assistant Professor of Psychiatry, Kurdistan University of Medical Sciences, Sanandaj, Iran; \\ Asrin1360@yahoo.co.uk
}

\begin{abstract}
Emotional intelligence is the ability to manage and control stress and anxiety, motivation, hope and optimism in the face of obstacles on the way to the target. The aim of this study was to investigate the relationship between emotional intelligence and emotional maturity in students at Kurdistan University of Medical Science 2016. This study was a cross-sectional study on 396 students of Kurdistan University of Medical Science. The instruments of this study were two questionnaires include Bar-on Emotional Intelligence Questionnaire and Emotional Maturity Scale, respectively. Results were analyzed using SPSS version 22 and statistical analysis use Liner regression and Pearsin Correlation. In this study, $53.3 \%$ were females and $46.7 \%$ were male. $58.6 \%$ of people in the age group 23-21 years. $46.2 \%$ of participates had grade point average in the range of 15-12. The correlation between emotional intelligence and emotional maturity and there was a significant relationship $(\mathrm{P}<0.001)$. Also, there was a statistically significant relationship $(\mathrm{P}<0.001)$ between the components of interpersonal emotional maturity, interpersonal, adaptability, stress management and general mood. Due to the positive effects of the relationship between emotional intelligence and emotional maturity, it is suggested however further studies on students identify factors associated with emotional maturity and careful planning in order to strengthen and increase the emotional intelligence of students take these factors.
\end{abstract}

Keywords: Emotional Intelligence, Emotional Maturity, Kurdistan University

\section{Introduction}

Human resource success throughout history has always been a matter for everyone, especially scholars and researchers from different fields and it has always been the question of what factors or factors make some people more successful than others? Since the middle of the 19th century, the subject of intelligence and mental ability of the successful people was at the center of attention of the researchers and considered it the main factor in the success of the people. However, over time, it has become clear that, although intelligence and cognitive abilities are in some ways related to progress and success, they are not the only predictor of success ${ }^{35}$. In fact, the intelligence of the individual alone cannot explain and guarantee the success of individuals in all the ups and downs of life and cannot make people well prepared for the right and proper problem ${ }^{29}$. Hence, researchers in recent decades have studied non-cognitive factors and have achieved significant success in determining non-cognitive factors ${ }^{35}$. They found that what have a key role in it are personal characteristics, creativity, ability to adapt to the environment, ability to work with others and encourage and encourage more activity ${ }^{29}$. In other words, various studies and studies indicate that the key to predicting success is not just cognitive intelligence, but also another type of intelligence that in the literature of psychology and education such intelligence is called emotional intelligence, which is typically referred to as It seeks to recognize and recognize the position of emotions and emotions and their important role in various mental and intellectual actions of man.

${ }^{*}$ Author for correspondence 
Emotional intelligence was discussed in the late $20^{\text {th }}$ century. Based on this notion of thought and excitement, as previously thought, are not separate. Emotional intelligence is the latest evolution in understanding the relationship between thought and emotion. Contrary to previous beliefs, the best and most unique contribution that this concept accomplishes is to think that the excitements and thoughts are combined and cleverly combines them ${ }^{16}$. In the study of Engelberg, emotional intelligence has been proposed as a general ability for emotional and social compromise. Emotional compromise can include good mental health, satisfaction with personal life and coordination between feelings, activities and thoughts ${ }^{28}$. Gellman believes that emotional intelligence is another aspect of intelligence that plays an important role in achieving people's ability to succeed in different aspects of life, more than cognitive intelligence. The roots of emotional intelligence can be found in Darwin's early work where he commemorates the importance of emotional tools for survival and adaptation ${ }^{4}$. Goleman (2007) believes that although IQ determines scientific progress and professional success, its contribution to such successes is less than 20\%; he says that emotional intelligence is the most important feature for distinguishing top managers from middle managers.

Emotional maturity is the result of natural emotional growth and the affected individuals are able to control their emotions and can endure their needs without being sorry and suffering ${ }^{34}$. An emotionally grown person has the capacity to withstand the needs of the lender; he is also able to withstand frustration and has the ability to plan for a long time or to rethink his expectations. He has the ability to control severe fluctuations and knows how to control his emotions ${ }^{27}$. According to Singh and Bhargava (1990), natural growth in emotional maturity is associated with issues such as emotional instability, social incompatibility, lack of independence and even emotional returns and anti-moral behaviors. While, due to emotional maturity, in addition to mental stability and balance, one's ability to recognize emotional priorities has grown and is able to control the emotional self-control by being independent of the ability of the person with emotional maturity; Insisting on others and instead of accepting the attitudes and patterns of others, they will better understand their attitudes and behaviors. Such a person comes up with some degree of emotional complexity that can find more complex solutions to his everyday emotional problems and use his feelings to grow up to solve problems. These people are capable of effective communication, able to manage their emotional resources and have high levels of coping power ${ }^{5}$. The most prominent symptom of emotional maturity is the ability to withstand tension and its other sign is the indifference to some types of stimuli that affects the individual and makes him feel bored and overwhelmed ${ }^{6}$. People with emotional maturity are those who control their emotional life well. Emotional damage can be exacerbated as a stressful situation in low affective puberty and in fact this psychological structure can be viewed as a protective factor ${ }^{3}$. Recent studies by cognitivists and therapeutic couples emphasize that among all factors, cognitive measures play a more important role in satisfaction and adaptation of close and intimate relationships, as well as among cognitive variables. Irrational expectations of couples and among noncognitive factors, emotional maturity plays an important role in the advent of marital relationship construction and close relationships ${ }^{22}$

In fact, someone who is emotionally mature does not necessarily solve all the causes of anxiety and hostility, constantly strives to revise his emotions in a clearer perspective, delay his expectations based on the need for a position and to achieve greater compatibility for strategy preparation. Struggle is more efficient. So he can tolerate a reasonable amount of failure, can rethink it ${ }^{18}$ and is able to properly use his emotional experiences in response to a stressful situation ${ }^{24}$. Such a person is more successful in confronting problems as it is equipped with a set of coping skills and capabilities, because in addition to its high ability to control emotional affliction due to the use of effective coping responses to overcome problems in interpersonal relationships and individual conflicts are more relevant and can be more successfull ${ }^{11}$. Emotional maturity is a process in which a person's personality constantly and psychologically tries to achieve emotional health ${ }^{31}$. Seven components of intimacy, empathy, self-expression, psychological stability, independence, psychological balance and the ability to observe the emotional affair as a complete definition of emotional maturity ${ }^{30}$. Emotional maturity results from the realization that nothing or anyone else can detect, provoke and angry, unless the person himself gives this permission to that or that person ${ }^{21}$. But puberty does not merely mean specific attitude and action, but also the ability to enjoy full enjoyment of them ${ }^{7}$. It is obvious, however, that in order to grow emo- 
Table 1. Distribution of Emotional Intelligence and Emotional Maturity

\begin{tabular}{|l|c|c|c|}
\hline \multirow{2}{*}{ Variables } & Frequency & Percent \\
\hline \multirow{3}{*}{ Emotional Intelligence } & High emotional intelligence & 140 & 35.4 \\
\cline { 2 - 4 } & Moderate emotional intelligence & 75 & 18.9 \\
\cline { 2 - 4 } & Low emotional intelligence & 181 & 45.7 \\
\hline \multirow{3}{*}{ Emotional Maturity } & Very stable & 2 & 0.5 \\
\cline { 2 - 4 } & Relatively stable & 2 & 0.5 \\
\cline { 2 - 4 } & Unstable & 12 & 3.03 \\
\cline { 2 - 4 } & Very unstable & 380 & 95.97 \\
\hline
\end{tabular}

Table 2. The correlation coefficient results of the variables of the study

\begin{tabular}{|c|c|c|c|c|c|}
\hline Hypothesis & Independent variable & $\begin{array}{c}\text { Dependent } \\
\text { variable }\end{array}$ & $\begin{array}{c}\text { Significance } \\
\text { level }\end{array}$ & $\begin{array}{l}\text { Correlation } \\
\text { coefficient }\end{array}$ & $\begin{array}{c}\text { Result of the } \\
\text { test }\end{array}$ \\
\hline $\begin{array}{l}\text { The main } \\
\text { Hypothesis }\end{array}$ & Emotional Intelligence & $\begin{array}{l}\text { Emotional } \\
\text { Maturity }\end{array}$ & 0.001 & 0.368 & $\mathrm{H}_{\mathrm{o}}$ is rejected \\
\hline $\mathrm{H}_{1}$ & In-person component & $\begin{array}{l}\text { Emotional } \\
\text { Maturity }\end{array}$ & 0.001 & 0.366 & $\begin{array}{l}\text { Ho is } \\
\text { rejected }\end{array}$ \\
\hline $\mathrm{H}_{2}$ & Interpersonal component & $\begin{array}{l}\text { Emotional } \\
\text { Maturity }\end{array}$ & 0.001 & 0.338 & $\mathrm{H}_{\mathrm{o}}$ is rejected \\
\hline $\mathrm{H}_{3}$ & Compatibility component & $\begin{array}{l}\text { Emotional } \\
\text { Maturity }\end{array}$ & 0.001 & 0.325 & $\mathrm{H}_{\mathrm{o}}$ is rejected \\
\hline $\mathrm{H}_{4}$ & Stress management component & $\begin{array}{c}\text { Emotional } \\
\text { Maturity }\end{array}$ & 0.001 & 0.329 & $\begin{array}{l}\text { Ho is } \\
\text { rejected }\end{array}$ \\
\hline $\mathrm{H}_{5}$ & Public mood component & $\begin{array}{l}\text { Emotional } \\
\text { Maturity }\end{array}$ & 0.001 & 0.329 & $\begin{array}{l}\text { Ho is } \\
\text { rejected }\end{array}$ \\
\hline
\end{tabular}

tion it does not depend only on the age of the birth certificate, but the psychological, social and emotional age and physical age are all factors that influence maturity. If these factors are eliminated, the best age for marriage is twenty-five years for men and twenty-two for women. A person with a real emotional growth about his wife, child, friends and life problems has a realistic view. He has a certain philosophy of life that can prevent permanent life-threatening situations. He relied on his current advancements and he did not rely heavily on his past, though magnificent. Meanwhile, she looks at things like sex, love, marriage and education with an intellectual child. Such a person has the power to control his feelings and emotions $^{32}$. 
Emotional intelligence is an intrinsic factor that, since its appearance, researchers have investigated their relationship with different spheres of life such as academic performance, deviant behavior, interpersonal relationships ${ }^{9}$ and the quality of marital relationships ${ }^{26}$. Meyer and Salvay (1990) defined emotional intelligence as the ability to recognize, use, perceive and manage excitement. Carroll (1993) also referred to emotional intelligence as the intrinsic and inherent ability of intelligence to refer to a hierarchy of mental abilities ${ }^{17}$. Some researchers also believe that emotional intelligence can facilitate psychosocial functions in various aspects of life $^{14}$. According to Hein (2007), emotional intelligence is the intrinsic ability to use feelings, communicate, recognize, remind, describe, identify, learn, manage, understand and understand emotions ${ }^{15}$. There is a lot of evidence that people who have emotional skills are privileged in every field of life ${ }^{25}$. Researchers in their research showed that acute intelligence students gain a higher score in terms of emotional intelligence components such as perceptions, acceptance, understanding and control over students with average intelligence ${ }^{23}$. Concerning the difference in emotional intelligence among gifted students and students with moderate intelligence, some studies show a significant difference between these two groups of students and some studies believe that these two groups of students in emotional intelligence differ there is no meaningful relationship with each other $^{20}$

According to the above, the purpose of this study was to determine the relationship between emotional intelligence and emotional maturity among students of Kurdistan University of Medical Sciences.

\section{Methodology}

In terms of data collection, this research is a descriptive type. Further, since in the study we attempt to determine the relationship between emotional intelligence and emotional maturity, this research is a co-relational research and considering data collection, it is a sectional research type that is conducted between the April and September of 2016. Since its goal is to determine the variables' correlation in Kurdistan University of Medical Science, it is a field study. The statistical population of the study in this research includes all students of Kurdistan University of Medical Science. The instruments of this study were two questionnaires include Bar-on Emotional
Intelligence Questionnaire (EQ-i) and Emotional Maturity Scale (EMS), respectively, which is stratified random sampling among 396 students. Cronbach's alpha coefficient for emotional intelligence and emotional maturity are 0.786 and 0.859 respectively, which represents the stability and internal consistency of the questionnaire. Results were analyzed using SPSS version 22 and statistical analysis use Liner regression and Pearsin Correlation.

\section{Findings}

In Table 1, the distribution of the variables of the research has been shown.

Table 1 shows that most of the subjects are in low emotional intelligence (45.7) and most of them are in a very unstable state (95.97) of emotional maturity.

Table 2. The correlation coefficient results of the variables of the study

According to the results of Table 2, at a 0.05 significant level, the hypothesis is confirmed and as a result, there is a significant relationship between the emotional intelligence and emotional maturity. The correlation factor is direct and equal to 0.368 i.e. with an increase in emotional intelligence emotional maturity increases. As in the above table, all research hypotheses are confirmed.

\section{Discuss and Conclusion}

The aim of this study was to investigate the relationship between emotional intelligence and emotional maturity in students of Kurdistan University of Medical Sciences in 2016. In the study, $53.3 \%$ of the pain was female and $46.7 \%$ were male. Our subjects were between the ages of 18 and 29, most of whom were 21-23 years old (58.6\%). The study population was with all students of faculties of medical sciences. The highest frequency was related to medical students with $33.3 \%$ and the lowest frequency was for paramedical students with $11.6 \%$. In this study, we examined the students' average score, which showed that the highest frequency was related to suffering from 15-17 with $44.7 \%$ and the lowest frequency was from 10 to 12 and above 19. In this study $35.4 \%$ of high emotional intelligence and $18.9 \%$ of the emotional intelligence was moderate and most of the subjects had $45.7 \%$ lower emotional intelligence. Also, the level of emotional maturity in the subjects was relatively stable at $0.1 \%$ and $3.03 \%$ were unstable and most of the subjects were highly insecure in terms of emotional maturity with $95.97 \%$. 
The first hypothesis was that there was a significant relationship between emotional intelligence and emotional maturity of the subjects. The results of linear regression analysis on the relationship between emotional intelligence and emotional maturity in students of Kurdistan University of Medical Sciences in 2016 showed that there was a significant relationship between emotional intelligence variables $(\mathrm{p}$ $=0.001$ ) and our first hypothesis Which is consistent with the results of studies ${ }^{(1,36)}$. In study Backshei (2008) the results showed that there is a significant relationship between emotional intelligence and mental health of students and their first hypothesis is confirmed that is consistent with our study. In this study, students with higher emotional intelligence have more control over the stressors. They have control over stress management and this ability helps them to be flexible in dealing with their problems and control their emotions. In the study by Tamanaifar et al., (2011), their results indicate that there is a positive and significant relationship between emotional maturity and self-knowledge. Therefore, students who have high emotional maturity and high self-knowledge, there is a greater sense of social security and there is a positive and meaningful relationship, that is, those who have less emotional maturity and lower self-knowledge, feel less socially. The study of the relationship between self-knowledge and emotional maturity showed that there is a positive and significant relationship between these two variables in the level of attitude. The study of Sheykhslamei et al., (2011) shows that there is a statistically significant relationship between emotional intelligence and student satisfaction. The interpretation of these findings suggests that students with high emotional intelligence have the ability to perceive, facilitate and cognize and regulating their self and others. Therefore, their interaction with the school's parents will be positive and effective and in dealing with the school environment alone, they will be able to maintain positive interaction with the teacher and the student by understanding the emotions above.

In the present study, the relationship between emotional intelligence and emotional maturity subscales was studied. The results are as follows. In our study, the relationship between in-person component (emotional self-awareness, self-esteem, self-esteem, self-esteem and independence) with emotional maturity was studied in the subjects. Results showed that there was a significant correlation between in-person component and emotional maturity $(\mathrm{P}=0.001)$, which results in similar studies $^{(8,19)}$. In a study by Livarjanei and Ghaffari (2010) emo- tional intelligence will have an impact on career and academic success. In his view, in the successful implementation of some occupational and educational assignments, the role of emotional intelligence is even higher than that of chastity.

The results of this study showed that there is a significant correlation between the interpersonal component which includes empathy, social responsibility and interpersonal relationships with emotional maturity in the subjects $(\mathrm{P}=0.001)$. In a study by Zahrakar (2007), the psychological components of youth and adolescents, such as emotional maturity and adolescence and social upgrading, should be developed to provide incentives for participation and collaboration at the national level. The capacity of the groups to act in favor of the community should also be increased, and all individuals must reach self-knowledge in order to create a good maturity and to be accepted into society and to create a coherence and integrity, thus creating social security.

In our study, there is a significant correlation between the compatibility component which includes (solving the problem of realism and flexibility) with the emotional maturity of the subjects $(P=0.001)$. People with higher emotional intelligence in their interpersonal relationships understand the messages better and have better listening skills and are more aware of the process of communicating with others and are more confident in their relationships and ultimately in Relationships with other people will be more successful ${ }^{33}$. The higher the level of compatibility in higher and higher individuals, the more they will have a more coherent intellectual maturity. Emotion is not necessary to understand and control the emotions and individual's emotions and feelings of others. According to Vayezenger (2000), emotional intelligence is the use of excitement and feeling of being guided by behavior, effective communication with friends and colleagues, supervisors, clients and how to use time and how to do work to improve productivity.

In the present study, there is a significant correlation between the stress management component (mental retardation and impulse control) and the emotional maturity of the subjects $(\mathrm{P}=0.001)$. So, the higher the amount of stress tolerance and the control of shaking in people, they will have higher intellectual maturity and will make more logical decisions in dealing with problems and issues. People with higher emotional intelligence for emotional reactions are more important and in the accounts they have more flexibility and liveliness and are on the path to success and it will be easier for them to tolerate their stress and control of their shaking. 
In the present study, there is a significant correlation between the components of public creation (optimism and happiness) and the emotional maturity of the subjects $(\mathrm{P}=$ 0.001). As much as people with higher intellectual maturity, the more optimism and happiness in people will be, the more they will be satisfied with life. The results of Anna et al., (2012) show a significant relationship between emotional intelligence and decision-making power and emotional intelligence can help a person make difficult decisions. In the study of Hassan et al., (2014), there was a significant relationship between emotional intelligence and communication skills and there was a significant and positive relationship between demographic variables (age and sex) and emotional intelligence.

In summary, we can say that today, many researchers (Zahrakar 2007; Zainab et al., 2011) believe that if a person is emotionally capable, he can better face life challenges and emotional abilities in identifying emotional responses in the face of everyday events. Expanding the range of insights and creating a positive attitude about events and emotions plays an effective role, so those who have the ability to recognize, control and use emotional will have greater social support, a sense of satisfaction and more mental health. According to the information obtained from the present study, emotional intelligence has a significant relationship with the factor's maturity of the subjects. In this study, emotional intelligence has been shown to enhance the emotional maturity of the subjects.

\section{References}

1. Anna Maria DF, Maureen EK. The contribution of emotiosa intelligence to decisional styles among Italian high school students. Caree Assessment. 2012; 20(4): 404-414. https://doi. org/10.1177/1069072712448893

2. Backshei L. Relationship between emotional intelligence, mental health and academic achievement. Research in Educational Planning. 2008; 1(19).

3. Bamelis LL, Evers SM, Spinhoven P and Arntz A. Results of a multicenter randomized controlled trial of the clinical effectiveness of schema therapy for personality disorders. American Journal of Psychiatry. 2014; 171(3): 305-22. https://doi.org/10.1176/ appi.ajp.2013.12040518. PMid:24322378.

4. Baron R. The bar-on model of emotional intelligence skills development traning, program and student achievement and retention. Unpublished Raw Data Texas A\&M University-Kingsville. 2006.

5. Bchera $S$ and Rangala B. Emotional maturity from dance practice: As a predictor towards life satisfaction in relation to selfesteem. Social Science International. 2014; 30(2): 237-249.

6. Cole DA and Rehm LP.Family interaction patterns and child- hood depression. J Abnorm Child Psychol. 1994; 14: 297-314. https://doi.org/10.1007/BF00915448.

7. Emrahim KH, Valilu M and Alireza L. The relation between quality of work life and job performance. Middle East J Sci Res. 2010; 6(4): 317-23.

8. Fetahei B and Negarpor S. A study of the relationship between emotional intelligence and self-esteem with social skills. Journal of Education and Evaluation. 2012: 6(23).

9. Ganth DB, Thiyagarajan S and Nigesh. Role of infertility, emotional intelligence and resilience on marital satisfaction among Indian couples. International Journal of Applied Psychology. 2013; 3(3): 31-37.

10. Goleman D. Social Intelligence. Bantam Books. N.Y. 2007.

11. Haj H, Mansoureh FJ and Maryam M. The effectiveness of teaching skills based on islamic approach on emotional maturity and tolerance in adolescent girls. Journal of Educational Sciences from the Viewpoint of Islam. 2017: 5(8).

12. Hassan J, Sacid J, Hashim F. The impact of emotional intelligence on communication effectiveness. Academic Journals. 2014; 6(5): 82-87.

13. Intelligence, self-efficacy and mental health and compare them with normal top students. Know and Res in Psychol, Islamic Azad Uni Khorasgan. 2008; 10(35\&36): 107-122.

14. Joseph DL and Newman DA. Emotional intelligence: An integrative met analysis and cascading model. Journal of Applied Psychology. 2010; 95(1): 54. https://doi.org/10.1037/a0017286. PMid:20085406.

15. Kaur J and Singh G. Alienation among urban adolescents in relation to emotional intelligence. International Journal of Allied Practice, Research and Review. 2015; 2(1): 32-36.

16. Khalili AH. Compare emotional intelligence of gifted and nongifted students and its relationship to academic achievement. Curriculum Planning. 2007; 21(14): 107-124.

17. Kong DT. Mayer-Salovey-Caruso Emotional Intelligence Test (MSCEIT/ MEIS) and overall, verbal and nonverbal intelligence: Meta-analytic evidence and critical contingencies. Personality and Individual Differences. 2014; 66: 171-175. https://doi. org/10.1016/j.paid.2014.03.028.

18. Lin D. and Lee C. Effectiveness of a mind training and positive psychology program on coping skills in school children in Taiwan. Journal of Child and Adolescent Behavior. 2015; 3 : 246-253.

19. Livarjanei $\mathrm{S}$ and Ghaffari S. The investigation of relationship between emotional intelligence and social skills with the educational progress of the second-grade light school students in Tabriz. Journal of Education and Evaluation. 2010: 3(9).

20. Livarjani SH and Golmohamadnejad G. Examine the relationship between emotional intelligence and social skills of gifted high school students and ordinary city of Khoy in the academic year 89-88. Eth Sci. 2009; 2(5): 185-210.

21. Live J. What is emotional maturity? 2017. Available from: http:// www.JonathanLive.com/jpg.Html.

22. Mahin, Torabi S, Mazaheri MA, Sahebi A and Mousavi V. The 
effect of cognitive behavioral adjustment unreasonable expectations, emotional maturity and marital satisfaction in women. Journal of Behavioral Sciences. 2010; 5(2): 21-40.

23. Mohammadamini Z, Barahmand $\mathrm{O}$ and Sobhigaramaleki N. The relationship between emotional.

24. Moritz S, Ludtke T, Westermann S, Hermeneit J, Watroba J and Lincoln TM. Dysfunctional coping with stress in psychosis. An investigation with the maladaptive and adaptive coping styles (MAX) questionnaire. Schizophrenia Research. 2016; 175: 129-135. https://doi.org/10.1016/j.schres.2016.04.025. PMid:27210727.

25. Moshe ZT, Shani-Zinovich I, Matthews G and Roberts R. Assessing emotional intelligence in gifted and no gifted high school students: Outcomes depend on the measure. Intelligence. 2005; 33(4): 369-391. https://doi.org/10.1016/j.intell.2005.03.001.

26. Nelis D, Quoidbach J, Mikolajczak M and Hansenne M. Increasing emotional intelligence: (How) is it possible? Personality and Individual Differences. 2009; 47(1): 36-41. https://doi. org/10.1016/j.paid.2009.01.046.

27. Nicholls AR, Levy AR and Perry JL. Emotional maturity, dispositional coping and coping effectiveness among adolescent athletes. Psychology of Sport and Exercise. 2014; 17: 32-39. https://doi.org/10.1016/j.psychsport.2014.11.004.

28. Oz H, Demirezen M and Pourfeiz J. Emotional intelligence and attitudes towards foreign language learning: Pursuit of relevance and implications. Procedia-Social and Behavioral Science. 2015; 186: 416-423. https://doi.org/10.1016/j.sbspro.2015.04.118.

29. Poon J. Emotional intelligence: For human resource managers. Journal of Management Research News. 2008; 25: 55-78.
30. Ramsden AC. Neuro psychotherapy. [Cited 2000 Jun 5]. Available from: http://weekendworkshops.com.au/profile/AncaRamsden

31. Safarpoor A. Investigation and study relationship between emotional maturity and marital adjustment of married men employed at Tehran Oil Pipelines Company with healthy and unhealthy perception of their original families. MS. Dissertation. Tehran: Shahid Beheshti University. 2007: 34-55.

32. Shamlou S. Mental health. 2nd ed. Tehran: Roshd. 2004: 11-14.

33. Sheykhslamei R and Ahmadei S. The relationship between emotional intelligence and student satisfaction. Journal of Research in Behavioural Sciences. 2011: 5(2).

34. Singh Y and Bhargava M. Manual for emotional maturity scale. Agra: National Psychological Corporation. 1991.

35. Stys Y and Brown SL. A review of emotional intelligence literature and implication for correction. Research Branch Correctional Servica of Cabada. 2004.

36. Tamanaifar MR, Sedighi SF, and Salami MAF. The relationship of emotional intelligence, self concept and self esteem to academic achivenment. IRPHE. 2011; 16(2): 99-113.

37. Zahrakar K. Investigating the relationship between emotional intelligence components and academic performance. Thought and Behavior. 2007: 2(5).

38. Zainab N, Seed H, Fazalur R and Nabi BJ. Impact of emotional intelligence on team performance in higher education institutes. International Online Journal of Educational Science. 2011; 3(1): $30-46$. 